\title{
Language Mirrors Culture With Speech Styles
}

\author{
ZHANG Jie \\ China Youth University of Political Studies, Beijing, China
}

\begin{abstract}
Knowledge of the culture difference in inter-cultural communicative is of primary importance. It is so in Sino-American communication, especially in speech, one of the two means of communication through language, with the other being writing. American and Chinese, brought up in different cultures, have different speech styles. Diversity in speech styles not only involves communication through verbal speech, but also through such non-verbal acts as kinesics, proxemics, and paralinguistic elements. Here the speech styles in the two cultures, American and Chinese, are contrasted with examples from a cultural perspective.
\end{abstract}

Keywords: language, culture, speech style, contrastive approach, cultural perspective

\section{Introduction}

Language is the mirror of culture. A certain language is certainly related with a certain culture, so languages should be studied in the cultures they are interwoven in, for language is the outcome of its culture, and meantime functions as a medium in the communication in different cultures. Communication is conducted and processed through language, which has two means - speech and writing. There is already many researches on the styles in the written form by others, so this thesis, will take "speech" as my focus. That is how language mirrors culture with speech styles.

\section{The Relationship Between Culture and Language}

It has long been recognized that language is an essential and important part of a given culture and that the impact of culture upon a given language is something intrinsic and indispensable. Whatever people may do when they come together or get contact with each other, they use language to express or exchange their ideas.

In a certain cultural system, every speech act, in this way or that, is affected by the culture. Though every person has his/her own style of speaking, the people living in the same culture certainly reveal a lot of similarities in the speech styles, and these differences are grown out of their cultures. This helps us distinguish one culture from another and helps a better inter-cultural communication. Being conscious of this, the different speech styles in American culture and Chinese culture are to be analyzed.

American people grow up in their "American Dream", the equality of opportunity and competition, material wealth and self-reliance, among which self-reliance is emphasized. Therefore, there are many words with the prefix "self-", such as "self-evident, self-acting, self-assumed, self-care, self-study..." a long list of "-self" words with the similar connotation of "being oneself", i.e., the individualism. The individualism can be seen nearly in every aspect of life. The Americans build their country, to coast the territory and to gain the

ZHANG Jie, associate professor, master, Department of Foreign Language and Literature, China Youth University of Political Studies. 
independence. Traditionally, they build their houses, their social status, their fame..., almost everything they want is to be DIY. When talking about the American individualism, LIN Yu-tang (林语堂) remarked, that they do not linger over their anxieties, instead, they stride ahead; they do not count on others, instead, they count on themselves; they do not sit there waiting for their opportunities, instead, they go out making their own opportunities. The Americans stress the uniqueness.

On the contrary, the Chinese are group-oriented. In a national questionnaire by YU Guo-ming (于国明), $61.3 \%$ of the people declare they favor the group honor; Chinese people put the interests of the family, the group, or even the nation as their first consideration. When facing conflicts, they mostly sacrifice and suppress their own wants to meet their superiors'. Individualism is considered presumptuous. Some western scholars name this "I-less culture". The inevitable result of this culture is that people rely much on others, on the cooperation and on the relationship. The informality is the key value of Chinese culture.

The typical characteristics of the Americans and the Chinese are grown out of their culture, and are much reflected in their speech styles, and meantime form their respective speech styles. Speech style can be verbal features and non-verbal features. In the verbal features, there are further divided into speech reciprocity, conversation structure, turn-taking conventions. In the non-verbal features, some detailed elements to be considered: kinesics, proxemics, paralinguistic elements, and culture assumptions.

\section{Verbal Features}

\section{Speech Reciprocity}

Speech reciprocity means a bilateral relationship between two or more elements, which make a conversation linked up. These elements include: in a conversation, which of the participants is more active, whether the duration of the pause of each speaker is the same; how each responds to the other's words or whether anyone changes the topic, etc.. Though in the same culture, people differ from one another in these aspects, generally speaking, the differences from different cultures are much more striking. Here is a conversation between one Chinese student (C) and an American teacher (A) in the classroom.

C: Can I ask you a question?

A: Sure.

C: What do you think of the " 9.11 " terrorist bombing?

A: er...

C: Well, eh, it started from an airport, I don't dare to take airplanes, and I fear a plane crash may happen. Did you fly here this term?

A: Yeah, well, I would say, I am sorry about that bomb. One of my friends died in it. (personal communication)

The Chinese student makes the American teacher quite awkward and hard to answer, for he is unaware that such topics as politics, age, salary, etc., are subtle and private, whereas, these are much talked about in China. When realizing the embarrassment, the Chinese student wants to change the topic though he really has a question, while the American goes back to hold the topic though he really does not want to.

\section{Conversation Structure}

Conversation structure means the way people state their core topic, their main idea, whether to state it at the beginning of the conversation or to put surrounding information or conditions first. This is affected by the different thought patterns in the different cultures. Many scholars are studying this, of whom the more 
influential one is Robert B. Kaplan (1967).

The Chinese thought pattern is cyclist. They tend to come to the main point from the general to the specific, from the whole to the part. They state their needs or key points from the relative background information or the relative topics to the main idea. It comes to the climax gradually, so this is called climaxing. This kind of structure leaves time for the listener to receive the main idea of the speaker in a gradual way, thus avoids abruptness. It is always formed with clauses, for example, clauses of reason, of condition, of concession at the front of their speech.

Chinese pattern:

—Because A, and because B, and because..., therefore/so...

-If... then...

-Although... but /yet...

Here is a conversation between a Chinese nutritionist (C) and an American nutritionist (A):

A: How do you decide what topic to do research on?

C: Because, now, period has got changed! It is different from the past. In the past, we emphasized on how to solve practical problems. Nutrition must know how to solve some deficiency diseases. In our country, we have same nutritional diseases, such as X, Y, Z. But now, it is important that we must do some basic research. So, we must take into account fundamental problems. We must concentrate our research on some fundamental research. (personal communication)

The Chinese put a lot of background information in the front, while the key points come last. And the American conversation structure is just the opposite. They tend to directly cut in, state their key points first, then to explain the reason, the conditions, process, or other. Instead of forming the climax gradually in a cycle, they tell the climax first, then to state the process, directly, in a linear way. It is called anti-climax. The following example can show the structure in the American way. This is a piece of talk about how climate affects culture. Climate affects the culture of a country (topic sentence).

So the general difference in constructing a speech in American English and Chinese can be shown in Table 1.

Table 1

The Language Style

\begin{tabular}{ll}
\hline American way of language style & Chinese way of language style \\
\hline Linear & Cyclist \\
Anti-climax & Climaxing \\
Stress on the process and why & Stress on the outcome and what \\
\hline
\end{tabular}

\section{Turn-Taking Conventions}

In a conversation, a listener cannot always be a listener. The participants are at the same time both listeners and speakers. Only with the interaction do the conversation work smoothly.

In order to make the listener understand, the speaker tends to simplify the language, use shorter and simpler sentences, slow down to leave some time for the listener to comprehend, or pause to leave a chance to be asked, or use proper body language, etc..

In order to better understand the speaker, the listener use these methods: make signs to show not understanding; interrupt with questions for once-more or further explanation; ask to slow down or more pause, 
etc.. In general, people take a free command of their native language. But different people from different cultures behave differently in the turn-taking.

If a Chinese and an American are talking in Chinese, generally, while listening, the Chinese seldom interrupts with questions, but usually nods; but while speaking, the Chinese leaves more time between sentences or between points. On the contrary, when compared with the Chinese, the American tends to ask if not understand, for example, "let me see, if I understand your main point..." (personal communication), and have less pauses, less time between sentences.

With the difference between Chinese and American in the turn taking with the conversation, the culture differences are auspicious. The Chinese are more tolerate while talking to foreigners, although they are quite clear about the points mentioned, whereas the American are more curious about the points not quite sure. The culture tells them to make sure what it is, while Chinese culture tells that to be listening to carefully is more polite than interrupting into the conversion.

\section{Non-verbal Features}

Non-verbal acts convey more information than verbal acts in the communication. It is estimated, there is $65 \%$ information is transferred through non-verbal acts, and only $7 \%$ is transferred through verbal acts. So, non-verbal acts are important in communication. The non-verbal acts may include body acts, hands acts, visual acts, proxemics, voice quality, voice set, dressing, posture, etc.. They are acts which can stimulate response in the oral communication, together with the verbal behavior. They can all be involved in transferring information. But the following non-verbal acts are those shared and featured in a culture.

\section{Kinesics}

Among the nonverbal conversation, kinesics is the main type that every part of the human body can convey information. It includes visual behavior, tactile behavior, olfactic behavior, posture, gesture, facial expression, and so on. In terms of kinesics, Americans and Chinese behave differently. For these behaviors are unconsciously acquired through culture.

(1) for example, "tongue out"

A-Americans use this act to show contempt.

C-Tibetans in China use this act to show their respect and politeness to the visitors, and the Hans in China use it to show their shock.

"crossed legs"

A-American men like to cross their legs to be at ease.

$\mathrm{C}$ - Chinese generally consider it as impolite to the guests.

(2) "visual behavior"

A-Americans regard direct eye-contact as being honest, attention. In communication, Americans always use eye-contact to show the interests in the topic, but not stare in an invariable, constant way of course. This conveys that "I am listening to you, but not getting into your privacy", and "I am equal to you".

$\mathrm{C}$ - The American way may seem quite rude to the Chinese. Chinese people do not look into other's eyes always, for it may cause unrest, awkwardness, or even offense.

(3) "facial expression"

When people are born, they carry out the first expression—crying. When cries, everybody shows his lips 
downward, no matter whether he is Chinese or American. It is no different, for facial expressions are genetic. People, from any place, show cries, smiles, angers, etc., in much the same way. But considering different cultures, people may carry different facial expressions toward the same object or event. That is decided by different cultures. The explanation can be illustrated by being encountering the word "running dog".

A-Americans may smile for their love of pet dogs.

C-It may arouse contempt, or anger in the Chinese, or may even a spit at it.

There is an experiment to show this difference. Two movies, one of which is amusing, the other being repulsive, are shown to Chinese and American students. Without strangers being present, the Chinese students make free facial expressions-laugh and despise casually.

But with strangers being present, they constrain their expressions more than the American students in the same condition.

\section{Proxemics}

The term "proxemics" can be defined as that: in communication, there is a special distance between people, the boundary of each one, which varies according to the degree of intimacy. This variation can be classified into:

(1) intimate distance.

It is between intimate friends, parents, and children, or those who have a very close relationship. It is within 0-1.5 feet. Within this distance, these acts may occur: touch, smell, and whisper, feel even each other's breath, or discover slight facial expression change.

(2) personal distance.

This is a transition from intimacy to general social distance with 1.5-4 feet or so. Touches or discovering slight facial expression changes may occur within this personal distance.

(3) social distance.

It is also called "politeness distance", at which most common communication or deal-making occur. It's at arm's length that is 4-12 feet, which is a safe distance. People may hear each other even in a low voice, but cannot discover the slight changes of facial expressions. And talk at this distance is mostly formal.

(4) public distance.

This is a communicative distance of $12-25$ feet in much more formal situation. Talking at this distance should not be in a low voice or whisper.

(5) long distance.

This is a public communication distance of 25 feet or more a public speech is addressed.

People communicate with different distance in accordance with respective culture. In China, people would like to narrow down the distance to show warmness and intimacy. Two young girls may take a walk hand in hand or arm in arm much within the intimacy distance, which may shock the Americans as homosexuals. In America, two friends do not walk much into the intimacy distance. Everyone has a distance, a boundary. They keep this even in queues. They may be stunned in the pushing and shoving in the Chinese queue for a seat in the library. Anyway, it is the condition and situation form the habitation. Accept it or reject it, being comparatively close is Chinese habit.

\section{Paralinguistic Elements}

Paralinguistics deals with the phonetic signals of non-verbal character, i.e., signals that cannot be 
linguistically segmented, as well as with their communicative functions, such paralinguistic elements are e.g., particular types of articulation and phonation (breathing, murmuring, whispering, clearing one's throat, crying and coughing), and individual types of language (pitch, timbre, rhythms of speech) and intonation. Trager (1965), a linguist, presented this term in his book Language in Culture and Society.

In terms of this, Chinese and American English are quite different. Chinese is tone language. Every character has a tone mark, which distinguishes meanings, for example, “摆脱 (bai tuo)”, “拜托 (bai tuo)”. However, the meanings of English words are distinguished by stress. For example, "CONTENT ['knntent]; [kən 'tent]". These are differences in acoustics respectively. This will cause difficulties in the inter-cultural communication between these two countries. When an American is talking with a Chinese in English, he/she will leave less time, or less pauses for his listener to better understand, for the English language has sentence stress and intonation to distinguish one sense group from another. While a Chinese is speaking to an American in Chinese, he will leave more pauses or time, for every Chinese character has a tone mark, and can be separated one after another in the speech.

"Clearing one's throat" is a particular articulation. In Chinese, it has various meanings. It can mean to have attention, to soften embarrassment, to inform somebody of one's coming, to prepare for the start of a speech, etc.. This avoids abruptness, whereas, the Americans mostly clear their throat to mean sorry.

\section{Cultural Assumptions With Some Idioms}

American and Chinese cultures have different values and world views. The following Table 2 is typical Chinese and American sayings, which show the typical characteristics and values of these two people.

Table 2

Values and Views and Cultures

\begin{tabular}{ll}
\hline Chinese & American \\
\hline What is possible depending on the circumstances? & All things are possible. \\
Greatness of a person is measured by one's humility. & It is the sneaky when that gets the oil. \\
When a man gets to top, his relations get with him. & You have to blow your own horn. \\
Birds that come forward are shot first. & Rolling stones do not gather moss. \\
\hline
\end{tabular}

These sayings richly reveal the differences between American and Chinese values. The table also tells that the different values make their speech styles different. When a Chinese receives praise, he always says "哪里, 哪里” (so-so), or “I just hit that chance". In contrast, an American will proudly say, "thank you".

So in inter-cultural communication, bear in mind the differences. e.g., if a Chinese assumes his listener (an American) has the knowledge about the tradition of dumplings, he will not rest on it when talking about dumplings and vice versa. This is true not only in speech, but also in written language, such as in translation, with or without a note.

\section{Conclusion}

For cultures being different, Chinese and Americans have different speech styles. The knowledge of the differences of these two peoples in their speech can avoid shock or clash in inter-communication. Though the inter-cultural studies are not a new field in conversation, it should draw more attention, interests, and efforts when doing the inter-cultural communication. 


\section{References}

Howell, R., \& Vetter, H. (1985). Language in behavior. New York: Human Science Press.

Hudson, R. (1981). Socio-linguistics. Cambridge: Cambridge University Press.

JIA, Y. X. (1997). The intercultural Communication. Shanghai: Shanghai Foreign Language Education Press.

Lyons, J. (1981). Language and linguistics: An introduction. Cambridge: Cambridge University Press.

Proxemics. (n.d.). In Wikipedia. Retrieved from http://en.wikipedia.org/wiki/Proxemics

Robinson, G. L. N. (1985). Cross-cultural understanding process and approaches for FL. Oxford: ESL and Bilingual Educators.

Robinson, G. L. N. (1987). Culturally diverse speech styles. In W. M. Rivers (Ed.), Interactive language teaching. Cambridge: Cambridge University Press.

The relationship between language and culture. (2012). Retrieved from http://www.doc88.com/p-993235027622.html 